\title{
Feminismo Transnacional: uma lente para o Anti-Orientalismo
}

\section{Do Muslim Women Need Saving?}

ABU-LUGHOD, Lila.

Massachusetts: Harvard University Press, 2013.

Vinte e três anos antes de os atentados de 11 de setembro acelerarem a circulação e aumentarem o entusiasmo por relatos e ficções que protagonizassem árabes e muçulmanos estereotipados sob uma cultura abjeta, Edward Said (1990) contribuía para a crítica anticolonia ao denunciar um determinado sistema europeu e eurocêntrico de conhecimentos sobre o "Oriente" como um corpo criado de teoria e prática com o objetivo de dominar, reestruturar e governar: o Orientalismo. Said, assim, expunha as relações de poder existentes entre a Europa e um conjunto de países a leste, maquiadas sob um estilo de pensamento binário Oriente/ Ocidente (bárbaro/civilizado, irracional/racional, feminino/masculino) que escondia interesses econômicos e políticos bastante específicos. Dentro de um projeto foucaultiano de traçar a relação entre poder e conhecimento, o autor argumentava que, para um europeu ou um estadunidense estudando ou debatendo o "Oriente", não poderia haver a negação de sua nacionalidade, pois ela não seria em si uma condição inerte. Devido ao Orientalismo, portanto, "o Oriente não era (e não é) um tema livre de pensamento e de ação" (SAID, 1990, p. 15).

O Orientalismo de Edward Said trouxe um importante aporte ao debate pós-colonial, tanto à crítica epistemológica das formas de produzir conhecimento quanto à denúncia das assimetrias globais de poder. Acadêmicas posteriores como Mohja Kahf (1999), Lisa Lowe
(1991), Meyda Yeðenoðlu (1998) e Reina Lewis (1996) apontaram o que se convencionou chamar "Orientalismo de gênero": a representação estereotipada da "mulher oriental" a partir de lentes europeias $e$ - especialmente - a representação desta mulher como oposição à "mulher ocidental". O mesmo Orientalismo, porém, trouxe consigo um importante desafio para os estudos feministas, assinalado pela antropóloga Lila Abu-Lughod, em Do muslims women need saving?, no sentido de pensar o feminismo em uma conjuntura global: feministas árabes e muçulmanas, especialmente aquelas que escrevem em inglês ou em francês, ao lançarem denúncias relativas a suas sociedades e governos, em um contexto de continuada hegemonia ocidental, podem incorrer no discurso orientalista; da mesma maneira, feministas europeias e norte-americanas, ao aceitarem o discurso dos direitos humanos universais, fazendo críticas ao que elas percebem como "a opressão da mulher oriental", podem contribuir para a legitimação de práticas políticas danosas. A razão disto é reiteradamente apontada pela autora: "Nós nos tornamos politizados sobre raça e classe, mas não cultura" (Lila ABU-LUGHOD, 2013, p. 47)'.

Do muslims women need saving? Resultou, justamente, da disjunção entre a experiência pessoal de Lila Abu-Lughod - tanto como antropóloga especializada no espaço árabe, como filha de pai palestino - e o que ela chama de o "novo senso comum": a percepção ocidental de que as mulheres muçulmanas são oprimidas e o são pela sua própria cultura. Tais representações elaboradas desde a perspectiva do Ocidente, porém, desviam o foco das forças sociais e políticas externas que são responsáveis pela maneira como as pessoas vivem a leste, incluindo-se, aqui, a pobreza resultante de uma divisão internacional do trabalho injusta e a 
militarização resultante do combate ao terrorismo. Ademais, mascaram o próprio debate e as lutas por justiça adstritas a esses países. Ainda, não raro a questão da mulher é instrumentalizada pela política colonial, a fim de justificar a intervenção política. A isso Leila Ahmed deu o nome de "Feminismo Colonial", que, sendo uma crítica à cultura de outros povos, promove o encontro entre as convicções brancas androcêtricas e paternalistas com as ideias feministas, a serviço do Império (AHMED, 1992)2.

As teorias feministas elaboraram críticas legítimas às noções estabelecidas de universalidade, imparcialidade e liberdade, as quais embasavam sistemas sociais excludentes (Anne PHILLIPS, 1995). Restam, porém, contradições a serem enfrentadas, principalmente quando trocamos a unidade de análise do local, regional, nacional, para processos e relações que atravessam fronteiras. Em uma era na qual a ideia de direitos humanos universais é não só amplamente aceita, como patrocinada por organizações internacionais, Abu-Lughod pergunta-se por que ser feminista significa combater parâmetros de opressão forjados no Ocidente ou por que o feminismo - por vezes - contribui para a construção de categorias abstratas como "a mulher muçulmana", "a mulher árabe", "a mulher oriental", consolidadas em grupos homogêneos sem contexto histórico, político ou geográfico (Jacayu M. ALEXANDER; Chandra MOHANTY, 1997).

Ao final, mulheres muçulmanas se veem sob um duplo enfrentamento: problematizar as construções patriarcais de suas identidades forjadas dentro de suas comunidades, em nível local (construções que em momento algum são negadas por Abu-Lughod), e também a política que se utiliza - em seu nome - do discurso do Orientalismo, em nível internacional. $\mathrm{O}$ antiOrientalismo, como um projeto político e também pedagógico, busca desenvolver contra narrativas críticas aos clichês que as representam e às suas culturas (Lisa K. TAYLOR; Jasmin ZINE, 2014).

A partir de exemplos de mulheres comuns habitantes principalmente do Egito e da Palestina, Lila Abu-Lughod constrói Do muslims women need saving? como narrativa anti-Orientalista, sem diminuir ou negar práticas machistas no Oriente, pretendendo apenas desmistificar concepções externas e generalizações pertencentes ao "novo senso comum". Assim, o livro se divide em seis capítulos. De princípio, Abu-Lughod faz uma interessante reflexão de como a Guerra ao Terror estadunidense acentuou 0 interesse sobre a situação das mulheres no Iraque e no Afeganistão, interesse sobre o qual ela opina que se deva permanecer cético, uma vez que o debate gravita sobre a religião, a burqa, as crenças e rituais, não havendo questionamentos sobre o que possibilitou a ascensão do Talibã, quais os interesses da intervenção dos Estados Unidos no Iraque, ou um debate qualificado sobre os efeitos da ocupação militar norte-americana na vida das mulheres locais. Nadje Al-Ali (2011), por exemplo, em um artigo seminal, retrata a recente luta das mulheres iraquianas para terem suas vozes ouvidas $^{3}$.

Nos capítulos subsequentes, Abu-Lughod detalha como são construídas e em que consistem as narrativas ficcionais ou relatos pessoais que dão origem à ideia de que mulheres muçulmanas são oprimidas. Ademais, como essas obras, a publicidade, os discursos políticos, impulsionam a cruzada moral, na qual encontramos, segundo as palavras de Gayatri Spivak "homens brancos salvando mulheres marrons de homens marrons" (SPIVAK, 1988, apud ABU-LUGDOD, 2013, p. 33$)^{4}$. Ao mesmo tempo, a autora apresenta diversas militantes e organizações dos países muçulmanos que buscam alternativas às injustiças segundo suas próprias experiências e convicções.

Assim, no debate entre universalismo e relativismo cultural, Abu-Lughod busca uma posição intermediária. A autora nega o universalismo, por engendrar as generalizações que nos impedem "de apreciar ou mesmo reconhecer as experiências das pessoas e as contingências com as quais todos vivemos" (ABU-LUGDOD, 2013, p. 17) ${ }^{5}$. Igualmente, a autora se opõe ao relativismo cultural, por perceber que as culturas não são estanques, homogêneas ou isoladas, sendo o produto de uma longa história de interações. Sobre o debate que intersecciona mulheres, relativismo cultural e o problema das diferenças, Abu-Lughod sugere que deva ser ponderado por três ângulos: (i) em primeiro lugar, é necessário que as feministas, especialmente as ocidentais, analisem quem elas estão apoiando (e quem não estão), pois apoiar o Feminismo Colonial empreendido por um dirigente que não foi eleito pelas suas posições progressistas relativas às mulheres é problemático. (ii) Em segundo lugar, as feministas devem aceitar a possibilidade da diferença; aceitar que as mulheres afegãs, mesmo após sua "libertação" do regime Talibã queiram coisas diferentes daquilo que o feminismo no Ocidente quer para elas. (iii) Em terceiro lugar, deve-se ser vigilante sobre a retórica de "salvar outros", que expressa uma atitude de arrogância. Ao final, as feministas no Ocidente devem analisar a sua própria responsabilidade, enquanto cidadãs em regiões privilegiadas do 
globo, pela situação na qual outras pessoas, em outras partes, se encontram.

Uma das mais interessantes lentes para a crítica ao Orientalismo de Gênero é o chamado Feminismo Transnacional, proposto por AbuLughod. Neste, às interseccionalidades de sexo, raça, classe deve ser adicionado o reconhecimento das assimetrias globais e das hierarquias de poder entre países. Ainda, busca-se realizar a análise das causas da subordinação de gênero dentro de contexto cultural específico, ressaltando-se história, memória e ética e recusando-se uma compreensão universalista das pretensas necessidades "da mulher" - que leva a uma visão das mulheres do Terceiro Mundo como "vítimas a serem salvas" - e também o artifício do relativismo cultural, que engessa as possibilidades de crítica à realidade de opressão de gênero (ABULUGHOD, 2013; Millie THAYER, 2009; ALEXANDER, MOHANTY, 1996). Essa "reinvenção" do feminismo como um projeto de políica transnacional, já apontado por Nancy Fraser (2007), adiciona criticidade também à disciplina Relações Internacionais, na qual é visível no seu mainstream teórico o ocultamento da questão de gênero (Fred HALLIDAY, 1999).

Eu tenho lido os trabalhos destas teóricas a fim de avançar no meu entendimento sobre as principais bases teóricas do Feminismo Transnacional e do Feminismo de origem árabe-muçulmano. O Feminismo Transnacional, o Feminismo Pós-colonial ou Feminismo Terceiro-mundista são criticados devido à sua falta de estratégias para a ação prática e por serem divisivos da unidade "mulheres" (Chris WEEDON, 1996). Considero essas críticas perniciosas. Seguramente, o discurso feminista avança através do encontro com as contradições em sua própria disciplina e militância. A denúncia, seja do Orientalismo, do racismo, do elitismo, refina a teoria e adiciona radicalidade à ação. Essa foi a intenção de Abu-Lughod: denunciar a manutenção e intensificação de um discurso danoso às mulheres pertencentes a uma realidade específica, a sua realidade, a fim de que o debate feminista não redunde no apoio àquilo que se opõe e que a militância ocidental possa contribuir efetivamente à militância que existe a leste ou ao sul. Ao final, os três ângulos levantados por Abu-Lughod devem ser levados em conta quando analisada uma realidade outra: deve-se considerar que discurso se estó apoiando, deve-se ouvir as vozes internas e devese questionar aquilo que universaliza uma realidade histórica, econômica, social complexa, tornando-a amorfa ${ }^{6}$.

\section{Notas}

1 Do original: "We have become politicized about race and class, but not culture".

${ }^{2}$ Do original: "Give an aura of moral justification to that as sault [on the religions and cultures of Other men, and in particular on Islam] at the very same time as it combated feminism within its own society".

${ }^{3}$ Ver também Thomas Plümper e Eric Neumayer (2006).

${ }^{4}$ Do original: "White men saving brown women from brown men".

${ }^{5}$ Do original: "From appreciating or even accounting for people's experiences and the contingencies with which we all live".

" Agradeço à professora Jussara Prá, da Universidade Federal do Rio Grande do Sul (UFRGS), pela aproximação aos Estudos Feministas e de Gênero e pelas trocas generosas.

\section{Referências}

ABU-LUGHOD, Lila. Do Muslim Women Need Saving?. Massachusetts: Harvard University Press, 2013.

AHMED, Leila. Women and gender in Islam: historical roots of a modern debate. New Haven: Yale University Press, 1992.

AL-ALI, Nadje. "A Feminist Perspective on the Iraq War". Works and Days, Pennsylvania, v. 29, n. 57, p. 99-113, jun. 2011. Disponível em: http:/ /www.worksanddays.net/201 1/File07.Al-Ali, N, 7.pdf. Acesso em: 16/02/2016.

ALEXANDER, Jacqyu M.; MOHANTY, Chandra T. Feminist Genealogies, Colonial Legacies, Democratic Futures. Nova York: Routledge, 1997.

FRASER, Nancy. "Mapeando a imaginação feminista: da redistribuição ao reconhecimento e à representação". Revista Estudos Feministas, Florianópolis, v. 15, n. 2, p. 291-308, maio/ago. 2007.

HALLIDAY, Fred. Repensando as Relações Internacionais. Porto Alegre: Editora UFRGS, 1999.

KAHF, Monja. Western representations of the Muslim woman: from termagant to odalisque. Austin: University of Texas Press, 1999.

LEWIS, Reina. Gendering Orientalism. New York: Routledge, 1996.

LOWE, Lisa. Critical terrains: French and British Orientalisms. Ithaca, NY: Cornell University Press, 1991.

PHILIPS, Anne. The politics of presence: the political representation of gender, ethnicity, and race. Oxford: Oxford University Press, 1995.

PLUMPER, Thomas; NEUMAYER, Eric. "The Unequal Burden of War: The Effect of Armed Conflict on the Gender Gap in Life Expectancy". Intemational 
Organization, [s.l], v. 60, n. 3, p. 723-754, jun. 2006

SAID, Edward W. Orientalismo: o Oriente como invenção do Ocidente. Tradução de Tomás Rosa. São Paulo: Companhia das Letras, 1990.

TAYLOR, Lisa K.; ZINE, Jasmin. Muslim Women, Transnational Feminism and the Ethics of Pedagogy: Contested Imaginaries in Post9/11 Cultural Practice. Nova York: Routledge, 2014

THAYER, Millie. Making Transnational Feminism: Rural Women, NGO Activists, and Northern
Donors in Brazil. Nova York: Routledge, 2009. WEEDON, Chris. Feminist Practice and Post structuralist Theory. Malden: Wiley-Blackwell, 1996.

YEĐENOĐLU, Meida. Colonial fantasies: Toward a feminist reading of Orientalism. Cambridge: Cambridge University Press, 1998.

[Recebida em 01/04/2016 e aceita para publicação em 25/04/2016]

Mariana Falcão Chaise Universidade Federal do Rio Grande do Sul, Porto Alegre, Rio Grande do Sul, Brasil

1030 Estudos Feministas, Florianópolis, 24(3): 1027-1030, setembro-dezembro/2016 